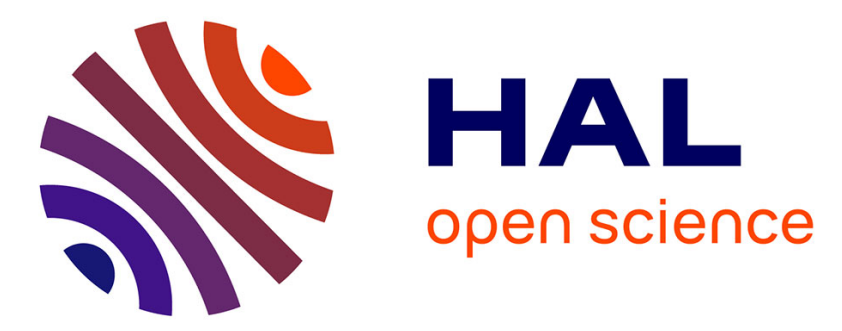

\title{
Eosin-mediated synthesis of polymer coatings combining photodynamic inactivation and antimicrobial properties
}

P. Sautrot-Ba, A. Contreras, S Abbad Andaloussi, T. Coradin, C. Hélary, N. Razza, M. Sangermano, P.-E. Mazeran, J.-P Malval, D.-L. Versace

\section{- To cite this version:}

P. Sautrot-Ba, A. Contreras, S Abbad Andaloussi, T. Coradin, C. Hélary, et al.. Eosin-mediated synthesis of polymer coatings combining photodynamic inactivation and antimicrobial properties. Journal of materials chemistry B, 2017, 5 (36), pp.7572-7582. 10.1039/c7tb01358b . hal-02121246

\section{HAL Id: hal-02121246 \\ https://hal.sorbonne-universite.fr/hal-02121246}

Submitted on 10 Jul 2019

HAL is a multi-disciplinary open access archive for the deposit and dissemination of scientific research documents, whether they are published or not. The documents may come from teaching and research institutions in France or abroad, or from public or private research centers.
L'archive ouverte pluridisciplinaire HAL, est destinée au dépôt et à la diffusion de documents scientifiques de niveau recherche, publiés ou non, émanant des établissements d'enseignement et de recherche français ou étrangers, des laboratoires publics ou privés. 


\title{
Eosin-mediated synthesis of polymer coatings combining photodynamic inactivation and antimicrobial properties $\dagger$
}

\author{
P. Sautrot-Ba, ${ }^{a}$ A. Contreras, ${ }^{a}$ S. Abbad Andaloussi, ${ }^{b}$ T. Coradin, (D) ${ }^{c}$ C. Hélary, ${ }^{c}$ \\ N. Razza, (D) ${ }^{d}$ M. Sangermano, (D) ${ }^{d}$ P.-E. Mazeran, ${ }^{e}$ J.-P. Malval ${ }^{f}$ and \\ D. -L. Versace (D) *a
}

Polymer coatings exhibiting photodynamic bacterial inactivation properties have been successfully engineered. Such coatings were obtained by photoinduced crosslinking of a PEG-diacrylate monomer associated with the eosin $Y$ dye which was used as both a radical photoinitiator and an antibacterial agent. A dual curing process was followed by combining compatible and solvent-free polymerization mechanisms, i.e. Aza-Michael reaction and free-radical polymerization in the presence of amines. The kinetics evolution of the photopolymerization process was followed using in situ Fourier transform infrared spectroscopy, allowing for the elucidation of the underlying mechanistic pathways. The influence of eosin $Y$ and amines on the thermal and mechanical properties of the films was evidenced and discussed in terms of crosslinking chemistry. The antibacterial properties of the coatings against two different strains (Escherichia coli and Staphylococcus aureus) were evaluated on short and long terms, revealing that eosin confers both photodynamic inactivation and antimicrobial properties to the films. These coatings are therefore particularly promising for disposable medical devices.

\section{Introduction}

Nosocomial infections are mainly due to the adhesion and the proliferation of bacteria on medical devices and are responsible for more than one hundred thousand deaths per year in the United States, strongly impacting the costs of the global health care. ${ }^{1,2}$ This raises the urgency of finding solutions to eradicate these problems, with a specific emphasis on the engineering of biomedical surfaces. ${ }^{3-5}$

\footnotetext{
${ }^{a}$ Université Paris-Est Créteil (UPEC) - ICMPE UMR CNRS 7182, 61, Avenue du Général de Gaulle, 94010 Créteil cedex, France. E-mail: versace@icmpe.cnrs.fr

${ }^{b}$ IEES Paris - UPEC, 61 av. du Général de Gaulle, Créteil, 94010, France

${ }^{c}$ Sorbonne Universités, UPMC Univ Paris 06, CNRS, Collège de France, UMR 7574, Laboratoire de la Chimie de la Matière Condensée de Paris, 4 place Jussieu, 75005 Paris, France

${ }^{d}$ Politecnico di Torino, Dipartimento di Scienza Applicata e Tecnologia, C.so Duca degli Abruzzi 24, 10129 Torino, Italy

${ }^{e}$ Laboratoire Roberval, CNRS, UMR 7337, Sorbonne Universités, Université de technologie de Compiègne, Centre de recherche Royallieu, CS 60319-60203 Compiègne cedex, France

${ }^{f}$ Institut de Science des Matériaux de Mulhouse, IS2M-LRC 7228, 15 rue Jean Starcky, 68057 Mulhouse, France

$\dagger$ Electronic supplementary information (ESI) available: Emission spectra of 4 xenon lamps used during different incubation times, redox potentials of LP and DETA, and TGA thermograms of photoinduced eosin-derived films (PELP, PEDET and PIEO) and the REF-PEG sample in air. See DOI: 10.1039/c7tb01358b
}

The use of a wide diversity of antibiotics appeared to be the treatment of choice for preventing bacterial infection since the discovery of penicillin by Fleming in 1928. However, the unnecessary and frequent use of antibiotics has led to an increase of healthcare problems associated with the increase of multi-drug-resistant bacterial strains. Indeed, a large number of antibiotics fail to prevent infections and cannot inhibit biofilm-associated bacterial formation. This biofilm acts as a defense wall, preventing the antibiotics to reach the bacterial structure, thus favouring their proliferation. It was estimated that 95000 invasive methicillin-resistant Staphylococcus aureus infections occurred in the United States and were responsible for more than 18000 deaths in $2005 .{ }^{6-8}$ In addition to this, clinical studies $^{9}$ have demonstrated the emergence of new $S$. aureus strains resistant to vancomycin which is currently considered as one of the most efficient glycopeptide antibiotics. In summary, alternative approaches need to emerge for efficiently treating biofilm related infections.

Antibacterial strategies are traditionally classified into two groups, depending on the interactions between the material and the targeted pathogens: ${ }^{10,11}$ the antifouling route that aims at preventing bacterial attachment on a surface ${ }^{12-14}$ and the antimicrobial strategy that promotes the killing of bacteria. ${ }^{15-21}$ Amongst the latter methods, the use of coatings producing reactive oxygen species upon light activation in the presence of 
a photosensitizer, ${ }^{22}$ termed antimicrobial photodynamic therapy (aPDT) ${ }^{23-27}$ is particularly promising. A great advantage of aPDT is to avoid the need to engineer delivery systems, as opposed to many antibiotics and inorganic antimicrobial agents. Moreover, as most biological systems are highly sensitive to reactive oxygen species, such surfaces can allow the reduction of the transmission of multi-resistant species such as bacteria, viruses, parasites and yeasts. ${ }^{26,28,29}$

Because biological systems are inherently complex, coatings with different functionalities may be necessary, to fully prevent bacterial proliferation. For instance, aPDT requires light activation, which is no longer possible after implantation. To address this issue, coatings combining complementary antibacterial mechanisms have been recently developed. ${ }^{30}$ The immobilization of the photosensitizers into polymer coatings opens the way for continuously "self-disinfecting" the surfaces in order to prevent infections. Many of the current investigations focus on the introduction of photosensitizers (PSs) by mixing solutions of PS in solvent with a polymer solution according to a solvent casting method. For example, methylene blue and rose Bengal dyes dissolved in chloroform have been embedded in polystyrene after air evaporation of the solvent to yield $15-140 \mu \mathrm{m}$ polystyrene films. ${ }^{31}$ The same procedure has been used to develop novel light activated antimicrobial coatings from the evaporation of acetone solutions of Toluidine blue $\mathrm{O}$ and Rose Bengal incorporated in cellulose acetate. ${ }^{32,33}$ A second interesting approach ${ }^{34}$ consisted of linking hydroxyl groups of polyol-derived porphyrins and isocyanate to polyurethane (PU) via a thermal polymerization. The resulting formulation has been sprayed via an air brush system onto polymethylmethacrylate substrates to form a $30 \mu \mathrm{m}$ PU-coating thickness. A third method described by Chen et al. has highlighted the use of PEG-coated gold nanoparticles (NPs) to deliver porphyrin-derived photosensitizer in a controlled manner. ${ }^{35}$ This opens the way for distributing a wide range of hydrophobic antibiotics. However, the non-covalent coupling reaction between PEG, gold colloids and the porphyrin-derived photosensitizers has to be performed under an argon atmosphere in the dark, in a complex and time-consuming multistep process.
In this context, we hypothesized that a single photoactive molecule could be used both to initiate polymerization and to confer antibacterial properties to the coating. We report here the synthesis of antibacterial coatings derived from PEG-diacrylate monomers under visible light illumination using eosin $\mathrm{Y}$, which is used both as a $\mathrm{H}$-abstraction photoinitiator ${ }^{36}$ and a photosensitizer generating ROS for aPDT, ${ }^{37}$ combining solvent-free polymerization mechanisms, i.e. Aza-Michael reaction ${ }^{38,39}$ and free-radical polymerization in the presence of amines as co-initiators under mild conditions. The kinetics of the film formation reaction were studied using in situ Fourier transform infrared (FTIR) spectroscopy, evidencing a two-step process. The optical, thermal and mechanical properties of the coatings were investigated, enlightening the key role of the amines in the structure of the polymer network. The antibacterial properties of the coatings against Escherichia coli and Staphylococcus aureus were evaluated on the short and long terms, with or without light irradiation, demonstrating that eosin Y can combine aPDT properties inside the film and antimicrobial properties upon release. A detrimental effect of the added amines on the antibacterial properties of the coatings was also observed and discussed. The here-demonstrated ability of the same molecule to play complementary roles at different time scales - i.e. during material preparation and on the short and long terms after contacting with bacteria - offers an original, easily implemented procedure occurring rapidly (less than ten minutes), in the absence of solvent, that should be highly inspiring for the future design of multi-functional antibacterial materials.

\section{Experimental}

\section{Materials}

All chemicals and reagents are used as received. Polyethylene glycol (PEG-diacrylate, $M_{\mathrm{w}}=400 \mathrm{~g} \mathrm{~mol}^{-1}$, SR344) was used as the diacrylate reactive monomer and was kindly provided by Sartomer. Eosin Y (EO, 99\%), Rose Bengal (RB, 95\%), 1,3-diphenylisobenzofuran (DBF, 97\%), diethylenetriamine (DETA, 99\%, $M_{\mathrm{w}}=103 \mathrm{~g} \mathrm{~mol}^{-1}$ ) and branched polyethylenimine-ethylene

Table 1 Structure of the monomer and photoinitiating systems used in this study

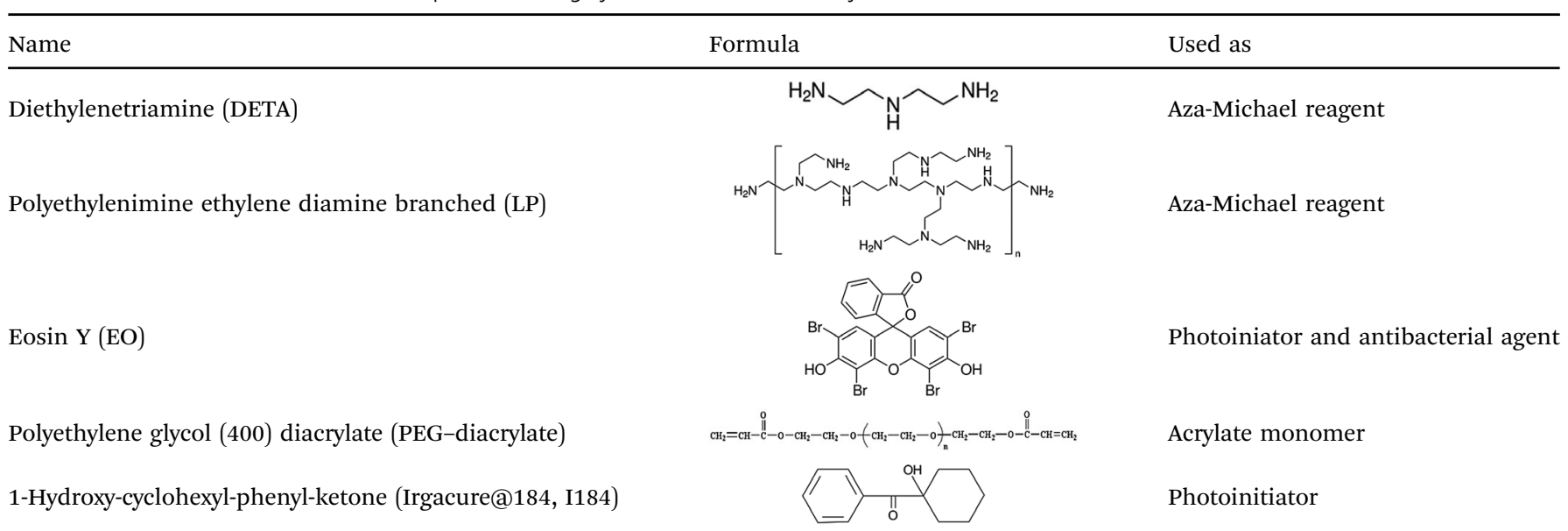


diamine (LP, 99\%, $M_{\mathrm{w}}=800 \mathrm{~g} \mathrm{~mol}^{-1}$ ) were purchased from Sigma Aldrich and 1-hydroxy-cyclohexyl-phenyl-ketone (Irgacure@184 (I184)) was provided by BASF. The chemical structures of the main compounds used in this study are displayed in Table 1.

\section{Sample preparation}

The amine-acrylate polymer consisting of a PEG-diacrylate mixture and a multifunctional amine (LP or DETA) were chosen to develop new antibacterial films. LP and DETA were selected to highlight the effect of the degree of branching of the amine on the antibacterial efficiency of the films. These films contain PEG-diacrylate, $7 \mathrm{wt} \%$ of amine (LP or DETA) and $0.1 \mathrm{wt} \%$ of eosin Y. After the first thermal stage of the reaction (Aza-Michael process), each formulation is laid down on a mould and irradiated for $1 \mathrm{~min}$. The thickness of the synthesized films is evaluated at $1 \mathrm{~mm}$.

Two reference films containing PEG-diacrylate monomers without amine were also synthesized to evaluate (i) the use of eosin $\mathrm{Y}$ and (ii) the influence of amino groups to inhibit the development of bacteria on the surface of the films under light activation. The first formulation contains PEG-diacrylate, $0.5 \mathrm{wt} \%$ of eosin $\mathrm{Y}$ and $3.5 \mathrm{wt} \%$ of a type I photoinitiator (I 184) called PIEO and the second reference film only contains PEG-diacrylate and $3.5 \mathrm{wt} \%$ of a type I photoinitiator (I 184) called PEG-REF. These films are irradiated using the same procedure described previously. For more clarity, Table 2 summarizes the nature of the different films which have been synthesized in this work.

\section{Steady-state photolysis experiments}

UV-vis spectra were recorded on a Varian spectrophotometer (Cary50 Bio) in the range of $250 \mathrm{~nm}$ to $800 \mathrm{~nm}$.

\section{Thermogravimetric analysis (TGA)}

Thermogravimetric analysis was carried out with a Mettler TGA/SDTA 851 instrument. Samples, obtained by dual curing with an approximate mass of $10 \mathrm{mg}$, were degraded between 20 and $700{ }^{\circ} \mathrm{C}$ at a heating rate of $10{ }^{\circ} \mathrm{C} \mathrm{min}^{-1}$ in air.

\section{Dynamic-mechanical thermal analysis (DMTA)}

Mechanical analyses were performed on a Triton Technology TTDMA in the tensile configuration. Samples of about $50 \mu \mathrm{m}$ thickness, $2 \mathrm{~cm}$ length and $0.5 \mathrm{~cm}$ width were prepared. All the experiments were conducted with a temperature ramp of $3{ }^{\circ} \mathrm{C} \mathrm{min}{ }^{-1}$, applying a force with a frequency of $1 \mathrm{~Hz}$ and a displacement of $20 \mu \mathrm{m}$. The storage modulus, $E$, and the loss

Table 2 Starting composition of the different films synthesized in this study

\begin{tabular}{llllll}
\hline Sample name & $\begin{array}{l}\text { PEG- } \\
\text { diacrylate }\end{array}$ & $\begin{array}{l}\text { Photoinitiator } \\
(\text { I184) }\end{array}$ & Eosin Y & LP & DETA \\
\hline REF-PEG & $\times$ & $\times$ & & & \\
PIEO & $\times$ & $\times$ & $\times$ & & \\
PELP & $\times$ & & $\times$ & $\times$ & \\
PEDET & $\times$ & & $\times$ & & $\times$
\end{tabular}

factor, $\tan \delta$, were measured from $-100{ }^{\circ} \mathrm{C}$ up to a temperature at which the rubbery state was attained. The $T_{\mathrm{g}}$ value was assumed as the maximum of the loss factor curve $(\tan \delta)$.

\section{Nanoindentation and scratch tests}

All experiments were made with a commercial Nanoindenter (Agilent Technologies G200) equipped with a Berkovich tip on steel substrate coatings. Twenty-five nanoindentation tests were performed using the Continuous Stiffness Measurement method (CSM). The loading stage was conducted at a constant stain rate $\left(0.05 \mathrm{~s}^{-1}\right)$ until an indentation depth of $3 \mu \mathrm{m}$ was reached. The load was then maintained constant for $60 \mathrm{~s} \mathrm{such}$ that the viscous response has enough time to achieve. Twenty parallel scratch tests distant from $500 \mu \mathrm{m}$ were performed at a scratch length of $500 \mu \mathrm{m}$. The tests were done face forward with a load that increases linearly from 0.1 to $100 \mathrm{mN}$.

\section{Fluorescence microscopy}

An inverted microscope IX73 from Olympus equipped with a $75 \mathrm{~W}$ Xe Lamp housing was used. The excitation and emission light was filtered with a fluorescence mirror unit (U-FUN from Olympus) including a band pass filter centered at $365 \mathrm{~nm}$ (BP360-370), a dichroic mirror (DM410) and a long pass filter (BA420IF).

\section{Real-time reaction monitoring using Fourier transform infrared (FTIR) spectroscopy}

During the first step of the Aza-Michael reaction, a Jasco FTIR spectrometer was used to monitor the evolution of the acrylate function during the isothermal dual curing at $35{ }^{\circ} \mathrm{C}$ of the formulations. Real-time spectra were recorded in the absorbance mode with a resolution of $4 \mathrm{~cm}^{-1}$ and a wavelength ranging from 400 to $4000 \mathrm{~cm}^{-1}$, averaging 10 scans for each spectrum. The spectra were normalized using the area of the carbonyl ester band at $1720 \mathrm{~cm}^{-1}$. The band at $1407 \mathrm{~cm}^{-1}$ (band of the $\mathrm{CH}_{2}$ scissor deformation mode) was used for monitoring of acrylate groups. ${ }^{40}$

In the second stage of the reaction, kinetics of photopolymerization were followed by real time Fourier transform infrared (RT-FTIR) spectroscopy using a JASCO series 4000 instrument. The liquid samples were applied to BaF2 chips by means of a calibrated wire-wound applicator. The thickness of the UV-curable film was evaluated at $100 \mu \mathrm{m}$. The RT-FTIR analyses were carried out under air conditions. Samples were irradiated at room temperature, by means of a Lightningcure LC8-02 lamp from Hamamatsu, equipped with a $\mathrm{Hg}$-xenon lamp $(200 \mathrm{~W})$ coupled with a flexible light guide. The end of this guide was placed at a distance of $6 \mathrm{~cm}$. The maximum UV light intensity at the sample position was evaluated to be $100 \mathrm{~mW} \mathrm{~cm}^{-2}$. The photopolymerization was monitored by the disappearance of the acrylate function of the diacrylate monomer at $1407 \mathrm{~cm}^{-1}$. The conversion rate was calculated using the followed equation (eqn (1)):

$$
\text { Acrylate conversion }(\%)=\left(A_{0}-A_{t}\right) / A_{0}
$$


where $A_{0}$ represents the area at $t=0 \mathrm{~s}$, and $A_{t}$ represents the area at any time $t$.

\section{Redox potentials}

The oxidation potentials of DETA and LP $\left(E_{\text {ox }}\right)$ were measured by cyclic voltammetry in $\mathrm{N}_{2}$-degassed acetonitrile with a constant concentration $(0.1 \mathrm{M})$ of $n-\mathrm{Bu}_{4} \mathrm{BF}_{4}$. A detailed description of the setup can be found in ref. 41. The free energy change $\Delta G_{\text {et }}$ for an electron transfer between the studied compounds and the amines can be calculated for the classical Rehm-Weller equation $^{42}$ (eqn (2)), where $E_{\mathrm{ox}}, E_{\mathrm{red}}$, ET, and $C$ are the oxidation potential of the studied compounds, the reduction potential of iodine, the excited (or triplet) state energy of the studied compounds, and the electrostatic interaction energy for the initially formed ion pair, generally considered as negligible in polar solvents:

$$
\Delta G_{\mathrm{et}}=E_{\mathrm{ox}}-E_{\mathrm{red}}-\mathrm{ET}+C
$$

\section{Antibacterial properties of the films}

Initial adhesion assays were performed using two strains of bacteria, namely E. coli ATCC25922 and S. aureus ATCC6538 on the eosin derivative-coatings. Prior to in vitro antibacterial tests, the bacterial strains were grown aerobically overnight in Luria-Bertani broth at $37{ }^{\circ} \mathrm{C}$ under stirring. Overnight cultures of $E$. coli and $S$. aureus grown in Luria-Bertani broth were diluted to an optical density (OD@600 nm) of 0.05 in sterile LB broth. At this point, the coated stainless-steel substrates $(1.5 \mathrm{~cm} \times 1.5 \mathrm{~cm})$ were immersed in the culture; the corresponding vials were placed on a slantwise rotating wheel to avoid the sedimentation of bacteria, incubated for $6 \mathrm{~h}$ and shaken at $150 \mathrm{rpm}$ to allow for initial adhesion (INFORS AG-CH 4103, Bottmingen-Basel, Switzerland). During the incubation time, some samples were illuminated under 4 Xenon lamps emitting in the visible range from 400 to $650 \mathrm{~nm}$ (intensity = $170 \mu \mathrm{mol} \mathrm{m} \mathrm{m}^{-2} \mathrm{~s}^{-1}$ ). The emission spectrum is given in Fig. $\mathrm{S} 1$ (see the ESI $\dagger$ ). Following adhesion, the samples were rinsed seven times with sterile saline solution $(\mathrm{NaCl}, 0.9 \% \mathrm{w} / \mathrm{v})$ to remove any non-adherent cells. Colonized native and treated samples were then transferred to $2 \mathrm{~mL}$ sterile saline (solution A) and vortexed vigorously for $30 \mathrm{~s}$. The samples were then transferred to $2 \mathrm{~mL}$ of sterile saline (solution B) and sonicated in a Branson 2200 sonicator for $3 \mathrm{~min}$. Samples were transferred once again to $2 \mathrm{~mL}$ of sterile saline (solution $\mathrm{C}$ ) and vortexed vigorously for $30 \mathrm{~s}$. Suspensions A, B and C were pooled and serially diluted, and the bacterial population was determined using the Plate Count technique as Colony Forming Units (CFU) per mL. Each experiment was done four times.

In a second series of tests, the bacteria were incubated for $16 \mathrm{~h}$ following the previously-described protocol. At this stage, one third of the samples were withdrawn. The rest of the samples were incubated for an additional $6 \mathrm{~h}$, half being left in the dark while the other half being illuminated under similar conditions as mentioned above. At the end of these experiments, the supernatant solution was recovered and the bacterial population was determined using the Plate Count technique as CFU $\mathrm{mL}^{-1}$. In parallel, the films were rinsed three times in PBS and incubated for $10 \mathrm{~min}$ in a live/dead assay mixture following the manufacturer's procedure (InVitrogen). Then, the films were rinsed three times in physiological serum for $5 \mathrm{~min}$ and mounted between the slide and the coverslip. Live and dead bacteria were observed using a fluorescence microscope Axio 100 (Zeiss). Live bacteria appeared in green after excitation of Syto 9 at 455-495 $\mathrm{nm}$ and detection at 505-555 $\mathrm{nm}$. Dead cells appeared in red after excitation of propidium iodide at $533-558 \mathrm{~nm}$ and detection at 570-640 $\mathrm{nm}$. Three films were analyzed for each condition.

\section{Results and discussion}

\section{In situ monitoring of the reaction}

The process leading to the Aza-Michael reaction and the free radical photopolymerization of the amine-acrylate formulations is described in Schemes 1 and 2. In the first step of the Aza-Michael reaction, which proceeds at $35{ }^{\circ} \mathrm{C}$, the amino groups of LP or DETA partially react with the acrylate functions (Scheme 1). In the second part of the process (Scheme 2), a photoinitiated free radical polymerization between the nonreacted acrylate groups occurs and results in a crosslinked material. The introduction of amino groups in the materials allows us to perform free-radical polymerization reaction in the second stage in air (Scheme 2): indeed, in the radical polymerization, the presence of $\mathrm{O}_{2}$ inhibits the polymerization $^{43-46}$ i.e. radicals $\mathrm{R}^{\bullet}$ which are generated during the initiation reaction are scavenged by oxygen to yield peroxyl radicals $\mathrm{ROO}^{\bullet}$ inactive towards the addition to acrylate double bonds thus limiting its use for practical applications. Eosin $\mathrm{Y}$ is a $\mathrm{H}$-abstraction photoinitiator which is generally associated with a co-initiator to produce radicals. Upon excitation, eosin $\mathrm{Y}$ is able to abstract a hydrogen atom from the co-initiator ${ }^{43}$ which acts as radical initiating species for photopolymerization.

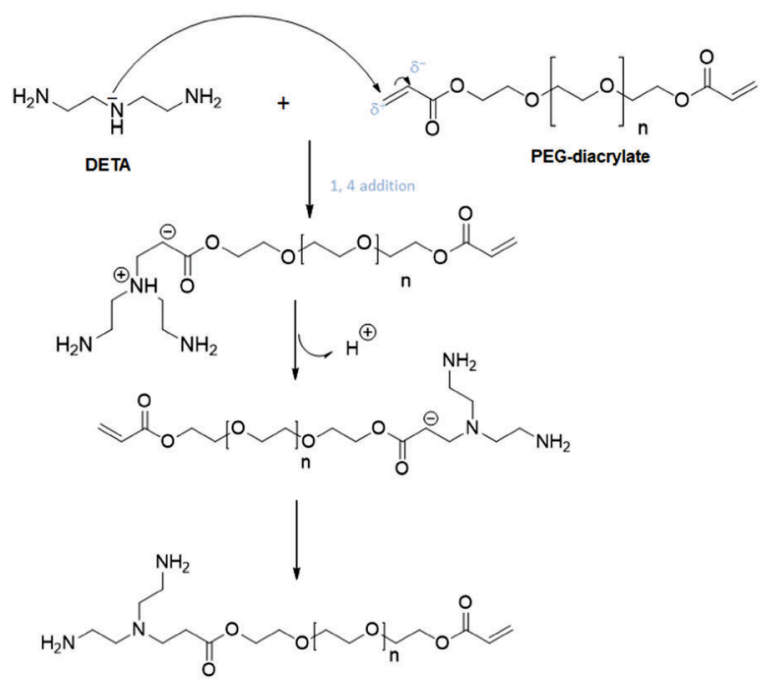

Scheme 1 Aza-Michael reaction between PEG-diacrylate and DETA at $35^{\circ} \mathrm{C}$. 


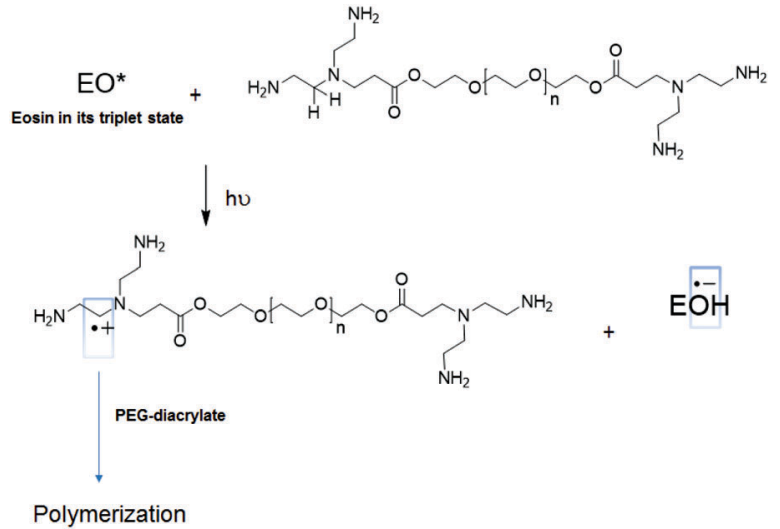

Scheme 2 Mechanism of polymerization with the photoinitiating system eosin/amine derivatives.

Tertiary amines ${ }^{43}$ are typically used as co-initiators. In this case, the reaction first involves an electron transfer from the amine to the triplet state of eosin (eqn (3)) followed by a proton transfer within an ion-pair formed between the amine radical cation and the eosin radical anion (eqn (4)). Therefore, when eosin and amines are combined together (eqn (3)), a dye-sensitized reaction occurs via an $\mathrm{H}$-abstraction mechanism under light activation, thus generating amino alkyl radicals and eosin radical-anions (eqn (4)) that can initiate polymerization. The photoinduced electron transfer between eosin (acceptor) in its triplet state and amines (donor) is thermodynamically allowed according to the classical Rehm-Weller equation ${ }^{42}$ (eqn (1)) since $\Delta G_{\text {et }}<0$ $\left(E_{\text {red }}(\text { eosin })^{47}=0.86 \mathrm{eV}, E_{\text {ox }}(\right.$ amine $)=0.58$ and $1.01 \mathrm{eV}$ for $\mathrm{LP}$ and DETA, respectively (see Fig. S2 in the ESI $\dagger$ ), and $\mathrm{ET}=1.89 \mathrm{eV}^{47}$ ).

Moreover, amino groups are considered as oxygen scavengers (eqn (5)) and the resulting peroxyl radicals may abstract hydrogen atoms from neighboring amino groups to follow the polymerization (eqn (6)).

$$
\begin{gathered}
{ }^{3} \mathrm{D}^{*}+\mathrm{AH} \rightarrow \mathrm{D}^{\bullet-}+\mathrm{AH}^{\bullet+} \\
\mathrm{D}^{\bullet-}+\mathrm{AH}^{\bullet+} \rightarrow \mathrm{DH}^{\bullet}+\mathrm{A}^{\bullet} \\
\mathrm{A}^{\bullet}+\mathrm{O}_{2} \rightarrow \mathrm{AOO}^{\bullet} \\
\mathrm{AOO}^{\bullet}+\mathrm{AH} \rightarrow \mathrm{AOOH}+\mathrm{A}^{\bullet}
\end{gathered}
$$

Fig. 1 shows the time dependency of the relative intensity of the acrylate FTIR bands during the Aza-Michael curing reaction. The following observations can be made: (i) the main reaction takes place during the first 20 minutes, (ii) a plateau is reached between 12 and 17 minutes and (iii) the polymerization kinetics of the DETA-derived formulations are faster and a higher degree of acrylate conversion is achieved than those containing branched polyethylenimine ethylene diamine (LP).

During the Aza-Michael reaction and especially when LP is used, the conversion is not complete (see Fig. 1, PELP): only $37 \%$ of the acrylate functions have reacted with amino groups. On the other hand, $28 \%$ of the acrylate function remains unreacted with the use of DETA (PEDET). This behavior can be associated with the steric hindrance of the polymer backbone

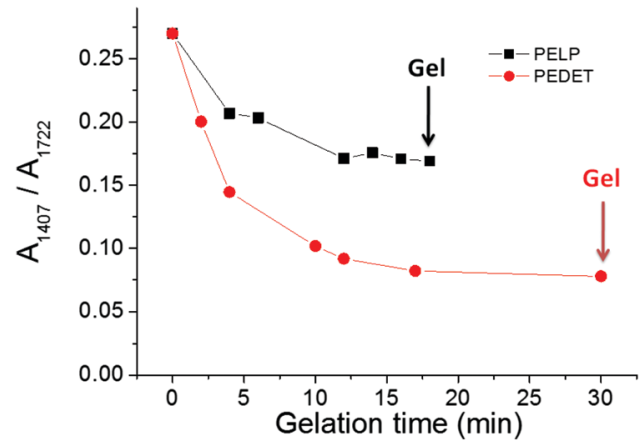

Fig. 1 Evolution of the acrylate band intensities (A1407/A1722) as a function of the gelation time and the nature of the amine used. Aza-Michael reaction at $35^{\circ} \mathrm{C}$.

which decreases both the reactivity of the secondary amines and the diffusion of the growing polymer chains. Wu et al. ${ }^{48}$ demonstrated, in a Aza-Michael addition polymerization with diacrylates, the higher reactivity of the primary amines in comparison with the secondary amines when the latter ones are sterically hindered. It can therefore be concluded that the difference between the reactivity of the LP and the DETA-derived materials is due to both the nature of the amine and to the accessibility of $\mathrm{N}-\mathrm{H}$ bonds.

Fig. 2 shows the kinetics of polymerization of the different formulations containing PEG-diacrylate during the second stage of the reaction. It is interesting to notice that the initiation stage of the amine-containing formulations in combination with eosin (PEDET and PELP) is slower than REF-PEG but the conversion of the acrylate functions reaches $100 \%$ after only $100 \mathrm{~s}$ of irradiation. Despite the fact that polymerization is carried out in air, amino groups play a major role as oxygen scavengers (eqn (5)) and new amino alkyl radicals are generated (eqn (6)), thus leading to a complete polymerization of PEG-diacrylate monomers. In the

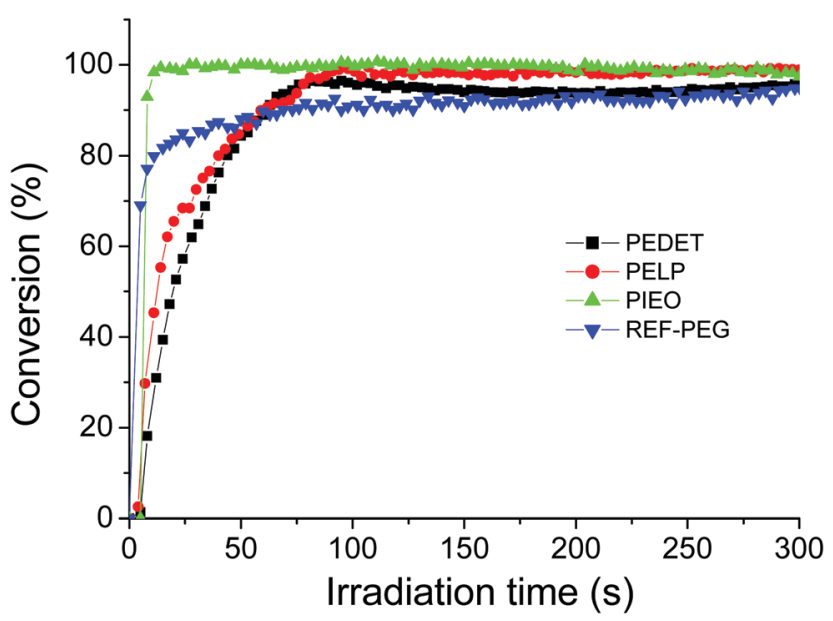

Fig. 2 Photopolymerization kinetics of formulations containing PEGdiacrylate: REF-PEG (PEG-diacrylate/l184 (3.5 wt\%)), PIEO (PEGdiacrylate/l184 (3.5 wt\%)/EO (0.5 wt\%)), PELP (PEG-diacrylate/EO (0.5 wt\%)/LP (7 wt\%)) and PEDET (PEG-diacrylate/EO (0.5 wt\%)/DETA (7 wt\%)). Irradiation under air atmosphere. $\mathrm{Hg}-\mathrm{Xe}$ lamp. Intensity = $100 \mathrm{~mW} \mathrm{~cm}^{-2}$ 
REF-PEG and PIEO systems that contain a type I photoinitiator (I184), $90 \%$ and $100 \%$ of the acrylate functions reacted after $100 \mathrm{~s}$ and $10 \mathrm{~s}$ of illumination, respectively. However, PEG-diacrylate is an $\mathrm{H}$-donor monomer and during the initiation step, a PEG-sensitized reaction may occur via an $\mathrm{H}$-abstraction mechanism, involving the PEG monomer and radicals (which are produced from the photolysis of I184) or eosin. Radicals could be generated on the PEG macromolecular chains from this $\mathrm{H}$-abstraction mechanism leading to side-reactions and consumption of acrylate functions.

\section{Optical properties of the films}

After $100 \mathrm{~s}$ of irradiation of the eosin-derived formulations or the REF-PEG system, different films have been synthesized. No fluorescence of the REF-PEG film has been observed. It has also been demonstrated that unreacted eosin dyes are preserved inside the films as indicated by their corresponding absorption and fluorescence spectra (Fig. 3). Therefore the presence of eosin suggests that its excitation could be used to promote singlet oxygen photogeneration with subsequent antibacterial effects.

\section{Thermal and mechanical properties of the films}

Fig. 4 presents the evolution of $\tan \delta$ with the temperature. Table 3 shows the thermal and mechanical properties of the

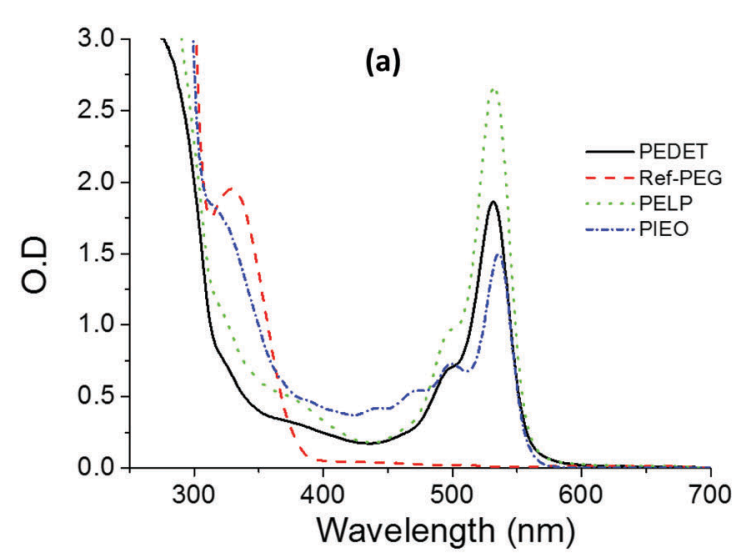

(b)
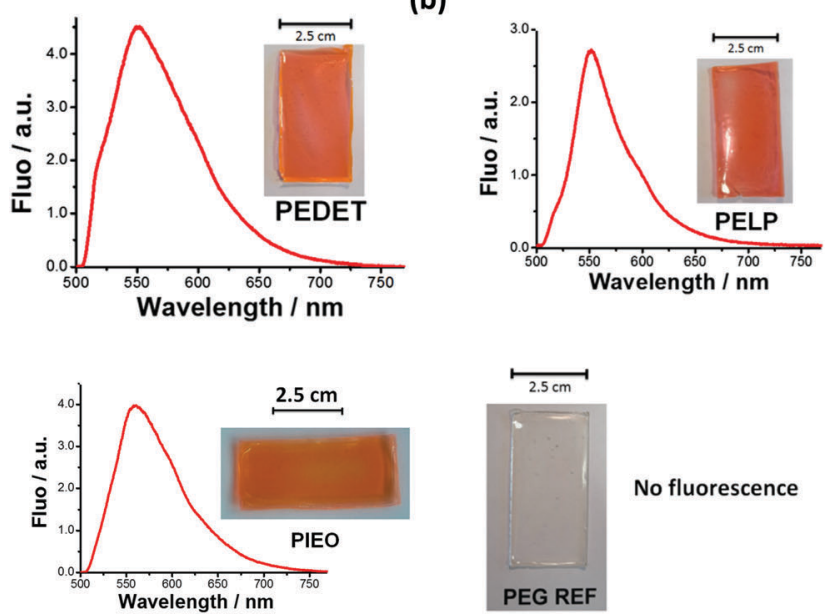

No fluorescence

Fig. 3 (a) UV-visible spectra and (b) fluorescence emission spectra of the different photosynthesized films (PEDET, PELP, PIEO, and REF-PEG). Thickness of the films $=1 \mathrm{~mm}$. Inset: Optical image of the films.

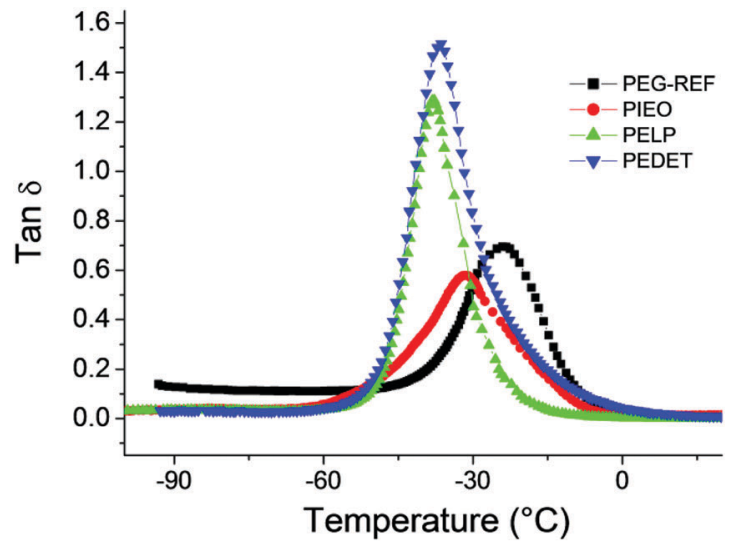

Fig. $4 \operatorname{Tan} \delta$ curves against temperature of eosin-derived films and REF-PEG sample.

Table 3 Thermal and mechanical properties of the eosin-derived films and REF-PEG sample

\begin{tabular}{llll}
\hline Samples & $T_{\mathrm{g}}\left({ }^{\circ} \mathrm{C}\right)$ & $\begin{array}{l}\text { Storage modulus } \\
\text { at } 25{ }^{\circ} \mathrm{C}(\mathrm{MPa})\end{array}$ & $\begin{array}{l}\text { Temperature } \\
\text { at } 50 \% \text { weight loss }\left({ }^{\circ} \mathrm{C}\right)\end{array}$ \\
\hline REF-PEG & -25 & 27 & 402 \\
PIEO & -30 & 18 & 401 \\
PEDET & -37 & 2 & 368 \\
PELP & -39 & 8 & 394
\end{tabular}

different photoinduced poly(acrylate)s-derived films which have been synthesized during the photopolymerization process. LP and DETA-derived formulations display lower $T_{\mathrm{g}}$ than those of poly(acrylate) networks, i.e. REF-PEG and PIEO. Highly crosslinked materials are thus synthesized when compositions contain a high proportion of acrylates (REF-PEG and PIEO). In contrast, for formulations containing amines (PELP and PEDET) in which the Aza-Michael reaction has occurred, a decrease of the $T_{\mathrm{g}}$ is observed and more loosely crosslinked materials are obtained. As a consequence, the stiffness of the films $E$ decreases in the following order $E$ (REF-PEG) $>E($ PIEO) $>$ $E$ (PELP) $>E$ (PEDET). Overall, the PEG-REF and PIEO films appear more rigid than the PELP and PEDET ones.

The thermal stability of the different networks has been studied using thermal gravimetric analysis (TGA) under an air atmosphere (see Fig. S3 in the ESI $\dagger$ ). Both polyacrylates and PELP films are more thermally stable than the PEDET one, the temperature at $50 \%$ weight loss being equal at $402{ }^{\circ} \mathrm{C}, 401{ }^{\circ} \mathrm{C}$ and $394{ }^{\circ} \mathrm{C}$ for REF-PEG, PIEO and PELP samples, respectively, and $368{ }^{\circ} \mathrm{C}$ for PEDET films. The degradation at low temperature $\left(368^{\circ} \mathrm{C}\right.$ ) for PEDET films is linked to poly(amino ester) degradation. Indeed, in the case of PEDET films, 74\% of the acrylate bonds have reacted according to the Aza-Michael reaction in the first step, leading to the formation of a poly(amino ester) structure which is less stable than a poly(acrylate) network. ${ }^{49,50}$ The higher degradation temperature of the REF-PEG, PIEO and PELP networks therefore reflects their higher content in poly(acrylate) chains.

The loading and unloading stages of the nanoindentation experiments lead to superimposed curves for all coatings 


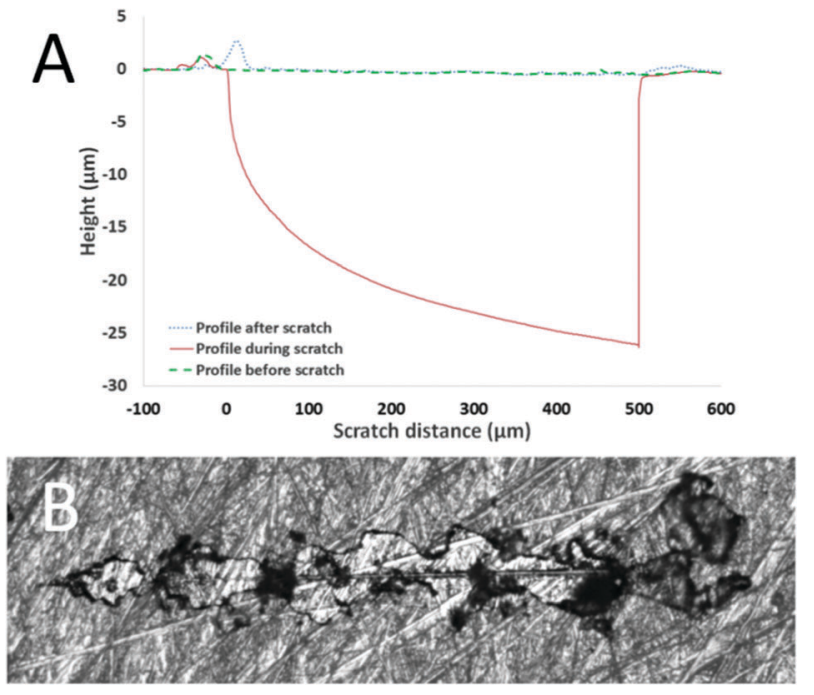

Fig. 5 (A) Height profiles measured before, during and after scratch experiment on PELP sample. A full elastic recovery could be observed indicating both a good fracture resistance and adhesion. (B) Optical image of the fracture and the delamination of the REF-PEG coating during scratch test.

evidencing quasi-elastic behavior. Thus, the four polymers are in the rubber-like state at room temperature and for a strain rate of $0.05 \mathrm{~s}^{-1}$. The Young's modulus was found to be 160 $( \pm 120)$ MPa for REF-PEG, $460( \pm 320)$ MPa for PIEO, $60( \pm 20)$ MPa for PELP and $60( \pm 50)$ MPa for PEDET. These differences can be explained by the different densities of branching structures which lead to the mobility restriction with a high stiffness, particularly in the REF-PEG and PIEO samples. Concerning the scratch resistance, the PELP coating shows a perfect elastomeric behavior without any delamination (Fig. 5), brittle fracture or residual imprint indicating both an excellent substrate adherence and an excellent resistance to fracture.

REF-PEG and PIEO coatings show brittle cracking indicating a moderate resistance to brittle fracture (Fig. 5, example of the REF-PEG coating). However, a scratch test on the PEDET coating results in delamination of the coating indicating a weaker adhesion to the substrate in comparison with the other coatings.

\section{Effect of light irradiation on bacterial colonization of the films}

The ability of the eosin-derived films PIEO to inhibit bacterial surface colonization by Gram-negative (E. coli) and Gram-positive (S. aureus) bacteria with and without light activation was first assessed on a short term scale, using PEG-diacrylate (REF-PEG) films as the reference (Fig. 6A). Initially, $3 \times 10^{6} \mathrm{CFU} \mathrm{mL}^{-1}$ of each type of bacteria was introduced in solution and brought into contact with the films. After $6 \mathrm{~h}$ of incubation, the films were rinsed, and the remaining biofilm population was detached and resuspended for cell counting. ${ }^{51,52}$ For $E$. coli, in the absence of illumination, more bacteria were found on the PIEO surface compared to REF-PEG. However, when the samples were illuminated for $6 \mathrm{~h}$, the reverse effect was observed due to a strong reduction of bacterial density on PIEO. These results are in good
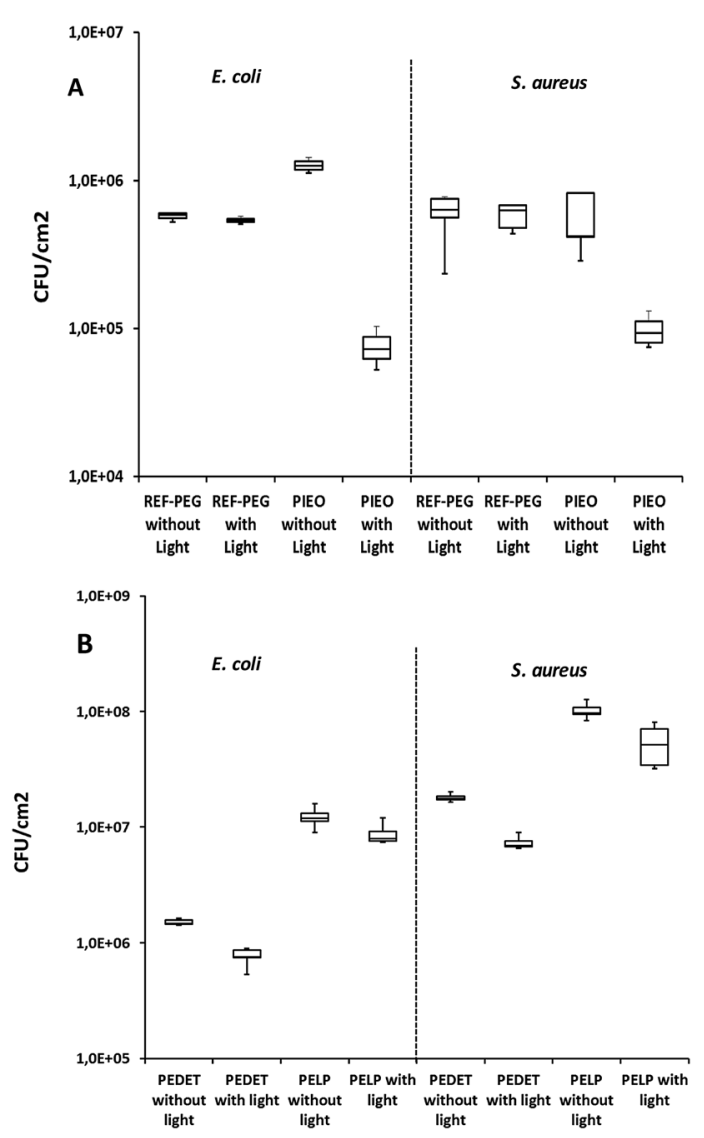

Fig. 6 Effect of visible light illumination and comparison of the antibacterial property of the different photosynthesized films after $6 \mathrm{~h}$ of incubation against $E$. coli and S. aureus. (A) REF-PEG and PIEO and (B) PEDET and PELP systems with and without illumination. REF-PEG = PEG-diacrylate/l184 (3.5 wt\%), PIEO = PEG-diacrylate//184 (3.5 wt\%)/EO (0.5 wt\%). Light illumination in the visible range. Film thickness $=1 \mathrm{~mm}$.

agreement with the well-known ability of PEG chains to prevent bacterial adhesion and also support the hypothesis that eosin has some antibacterial photoactivity. ${ }^{53}$ Indeed, if a large amount of singlet oxygen is created near the outer membrane of the bacteria, it will ultimately lead to its death. ${ }^{54}$ These results concerning the elaboration of singlet oxygen will be discussed in the next section and will confirm the antibacterial properties of our coatings.

However, for $S$. aureus, the two films showed a similar behavior in the absence of illumination, with a noticeably lower bacterial density on PIEO compared to E. coli. Upon illumination, the bacterial density only decreased significantly for PIEO. Altogether, these data would suggest that $S$. aureus has a lower affinity for the PIEO surface than E. coli and is therefore less impacted by its photoactivity.

Fig. 6B shows the influence of the amines on the bacterial population found on the surface of PEDET and PELP films after $6 \mathrm{~h}$ under light activation. A first observation is that bacterial density was lower on PEDET films compared to PELP but higher than on REF-PEG, whatever the light conditions and the considered bacterial strain. Moreover, light illumination only slightly decreases the bacterial population after $6 \mathrm{~h}$ for both films and both strains. This suggests that the presence of 
amines favors bacterial adhesion and decreases the photodynamic inactivation properties of the films.

Previous works have suggested that the elimination of hydrogen bond donor groups by acetylation of amino groups strongly decreases the resistance of the film surfaces to the adsorption of bacteria. ${ }^{5,56}$ The acetylation of hyperbranched amines turned hydrogen bond donor groups into hydrogen bond acceptor groups, thus resulting in a surface with lower affinity for proteins compared to non-acetylated surfaces, limiting bacterial proliferation and biofilm formation.

One possible explanation for the weaker effect of light irradiation is the deactivation by amino groups of the singlet oxygen which is generated under light illumination inside eosin-derived films. Indeed, the singlet oxygen can be quenched by DETA or LP inside the films, thus reducing the concentration of singlet oxygen at the surface of PELP and PEDET. To clarify this point, the quantum yield for singlet oxygen generation $\left(\Phi_{\Delta}\right)$ upon excitation of eosin (EO) has been evaluated in ethanol based on a photooxidation method using diphenylbenzofuran (DBF) as an ${ }^{1} \mathrm{O}_{2}$-sensitive indicator. Rose Bengal ${ }^{15}$ was employed as a standard photosensitizer $\left(\Phi_{\Delta}^{\circ}=0.68\right.$ in ethanol). Fig. 7 displays the typical evolution of the absorption spectrum of DBF in ethanol in the presence of either eosin $\mathrm{Y}$ or Rose Bengal during photolysis. Isoabsorbing solutions at $525 \mathrm{~nm}$ containing $\mathrm{EO}$ and $\mathrm{RB}$ were irradiated with an irradiance of about $9 \mathrm{~mW} \mathrm{~cm}^{-2}$. Both ethanolic solutions contained DBF at $5 \times 10^{-4} \mathrm{M}$. The absorbance of DBF at $412 \mathrm{~nm}$ recorded at different irradiation times is displayed in the insets of Fig. 7. The value of $\Phi_{\Delta} / \Phi_{\Delta}^{\circ}$ is obtained from the ratio of the corresponding slopes at the initial time of irradiation. A value of 0.43 is therefore measured for the ${ }^{1} \mathrm{O}_{2}$ photogeneration quantum yield by EO in ethanol which is in line with the results previously measured by Tanielian et $a .^{57}$

The same experiment was performed in the presence of a large excess of amines, DETA or LP respectively. The absorbance of DBF at $412 \mathrm{~nm}$ was recorded at different irradiation times as

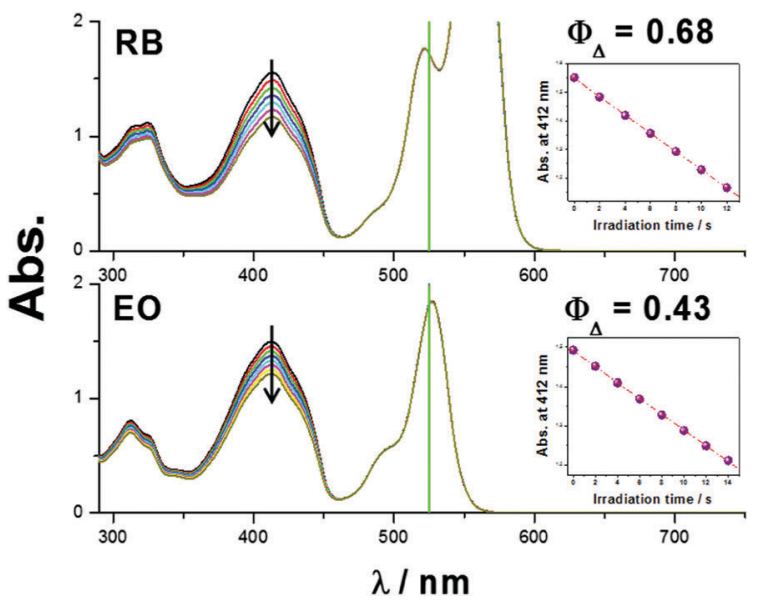

Fig. 7 Evolution of the absorption spectrum of ethanolic solutions of 1,3-diphenylisobenzofuran (DBF, $c=5 \times 10^{-4} \mathrm{M}$ ) mixed with eosin $\mathrm{Y}(\mathrm{EO}, \mathrm{c}=$ $1.65 \times 10^{-5} \mathrm{M}$ ) or with Rose Bengal (RB, $c=7.1 \times 10^{-5} \mathrm{M}$ ) upon irradiation at $525 \mathrm{~nm}$. The respective concentrations of $\mathrm{EO}$ and RB have been adjusted in order to have the same absorbance at the irradiation wavelength.

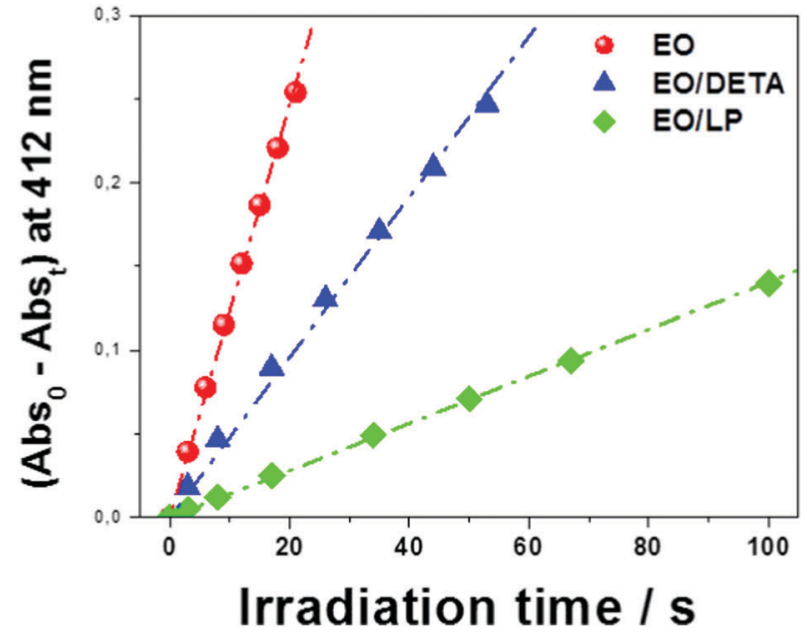

Fig. 8 Photooxidation of 1,3-diphenylisobenzofuran (DBF) at $412 \mathrm{~nm}$ and increase of the singlet oxygen concentration as function of the irradiation time $\left(\lambda_{\mathrm{ex}}=525 \mathrm{~nm}\right)$. [DBF] $=5 \times 10^{-4} \mathrm{M}$ in ethanol. $[\mathrm{EO}]=1.65 \times 10^{-5} \mathrm{M}$, $[\mathrm{DETA}]=0.044 \mathrm{M},[\mathrm{LP}]=0.0045 \mathrm{M}$.

displayed in Fig. 8. One clearly observes that the presence of DETA or LP induces a 2.5- and 9-fold decrease of the photooxidation rate of DBF, respectively. It should also be emphasized that LP induces a much significant inhibiting effect even if it has been added at a concentration 10 times lower than DETA. In both cases, the presence of amines as electron donor reactants opens up new additional competing reaction pathways: (i) dynamic quenching of both eosin singlet and triplet excited states, (ii) H-transfer reaction between the amines and the eosin triplet state which produces $\alpha$-amino alkyl radicals, (iii) redox reaction between highly reducing $\alpha$-amino alkyl radicals and photogenerated singlet oxygen and redox reaction between the amines and the photogenerated singlet oxygen.

\section{Role of eosin in the antibacterial properties of the film}

Previous experiments have demonstrated the efficiency of eosin to act as a photodynamic bacterial inactivation during the colonization process. In a step further, we wished to explore the performance of PIEO films, in particular their ability to exert an antibacterial effect after colonization has occurred. With this purpose, bacteria were first brought in contact with REF-PEG and PIEO films in the absence of light for $16 \mathrm{~h}$. At this stage, the cell population in the bacterial suspension was measured using CFU plate counting and the bacterial density was determined using a dead/live kit. It is worth noting that because of the overlap in the fluorescence spectra of eosin and propidium iodide, the precise determination of the number of dead bacterial cells was difficult. Keeping this limitation in mind, we never did observe a significant number of dead bacteria on the surface of the coatings, whatever the conditions. As shown in Fig. 9, E. coli and $S$. aureus bacteria were still visible on the REF-PEG film, with a higher density of the former compared to the latter, but the number of cells per observation field was in both cases very low. As a comparison, none of the two strains could be detected on PIEO surfaces. In parallel, 

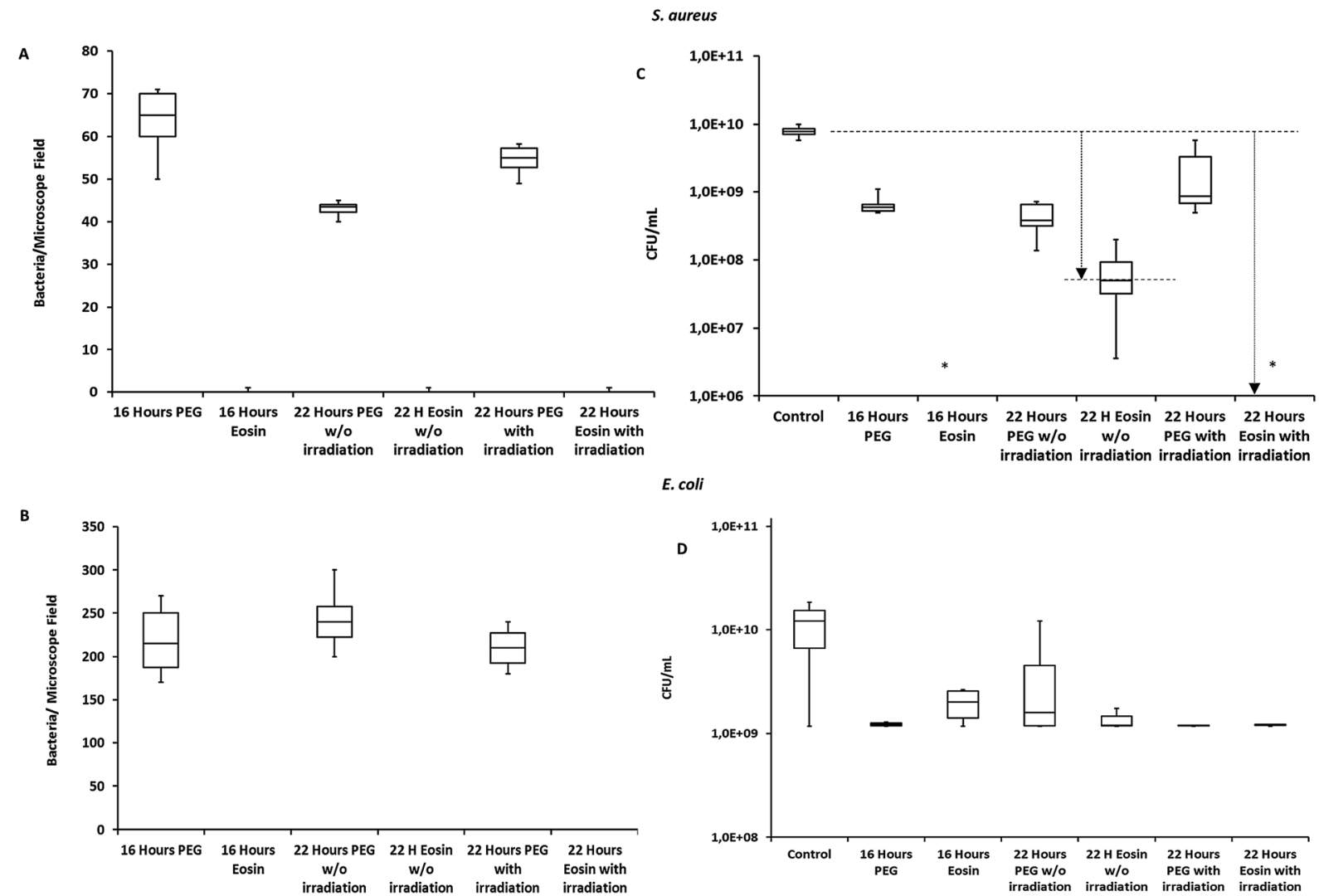

Fig. 9 Evolution of the number of bacteria on REF-PEG and Eosin-containing PIEO films on the surface of the films (A and B) and in the supernatants of these films ( $C$ and $D)$ after $16 \mathrm{~h}$ in the dark and $6 \mathrm{~h}$ in the dark or under illumination. Dashed lines and arrows show the killing efficacy. * indicate that the

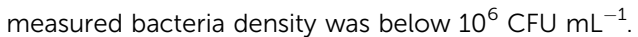

the $S$. aureus population in the suspension was decreased by one log with REF-PEG and completely disappeared with PIEO. On the other hand, both REF-PEG and PIEO had a similar and small (i.e. one log decrease) effect on the E. coli suspension. Noticeably, we also observed that the PIEO supernatants turned highly coloured, suggesting that some eosin had leached out of these films over the time of the experiments.

Additional experiments were performed where the films were left in contact with the bacteria without light for $16 \mathrm{~h}$, as described above, and then kept for an additional $6 \mathrm{~h}$ without or with illumination. At this stage, there was still no evidence of bacterial presence on the PIEO surface whereas small variations in cell number were found for REF-PEG with or without illumination depending on the bacterial strain (Fig. 9A and B). Turning to the film supernatant, illumination had a strongly negative effect on the $S$. aureus suspension in the presence of PIEO, but not in the presence of REF-PEG (Fig. 9C). In contrast, light had a negligible impact on $E$. coli populations in the presence of both films.

To explain these observations, the extent of bacterial colonization of the films arises from two possible processes: (i) the chemical/physical interactions between the bacteria and the surface and (ii) the toxicity of eosin either in the film or in solution, since leaching can occur. Hence, a low cell density on the film can indicate either a repulsive surface or a bactericidal effect, or both. As pointed out earlier, the REF-PEG surface has demonstrated a very strong ability to avoid bacterial adhesion. Our observation that, without light, E. coli bacteria are present after $6 \mathrm{~h}$ on PIEO but not after $16 \mathrm{~h}$ and $22 \mathrm{~h}$ is in favor of the prevalence of a bactericidal effect confined to the film surface when eosin is present, since the population of bacteria in the suspension does not vary significantly over the same period. For $S$. aureus, we noticed initially a lower cell density, comparable to REF-PEG. This can indicate a lower affinity of this bacteria to the PIEO surface, a higher sensitivity to its eosin-induced bactericidal effect or both. We observed the dramatic decrease of $S$. aureus population in the PIEO supernatant after $16 \mathrm{~h}$, which strengthens our hypothesis to the higher sensitivity of $S$. aureus to eosin compared to that of $E$. coli, without light. Our results are in agreement with Miller's investigation ${ }^{58}$ based on a survey screening of 30 different bacterial strains (including $E$. coli and $S$. aureus) against 42 different dyes at various concentrations, demonstrating the possible inhibition growth of Gram-positive bacteria over time by eosin Y without light illumination. This is also in good agreement with the fact that eosin is known to inhibit the growth of Gram-positive bacteria, such as $S$. aureus, while allowing for the staining of living Gram-negative bacteria, such as E. coli. ${ }^{59}$ Thus, the difference between the inhibition growth of $S$. aureus in comparison with $E$. coli is likely due to an accumulation of eosin at the film surface during its release, leading to high local doses which becomes toxic for both types of bacteria. 
Noticeably, the reason behind the difference of action of eosin towards Gram-positive and Gram-negative bacteria under light illumination is that only Gram-positive bacteria (S. aureus) are affected by an oxygen singlet process. Indeed, the lipopolysaccharide (LPS) coatings of the cell wall of the Gram-negative bacteria offer protection from the cytotoxic effects of the ROS agent. ${ }^{60,61}$ LPS in Gram-negative bacteria not only plays a role as a structural barrier to penetration but can also form a trap for singlet oxygen which is known to oxidize unsaturated fatty acids and proteins. ${ }^{54,62}$ Since $S$. aureus strains fail to produce a large proportion of LPS, they remain much more sensitive than E. coli to ROS penetration. ${ }^{54}$ As a result, singlet oxygen probably diffuses more readily through the open structure of the peptidoglycan layer of the $S$. aureus cell membrane to react with its vital target. In summary, the ability of PIEO to release eosin (i) prevents bacterial colonization of the film surface in the absence of illumination and (ii) allows for $S$. aureus bacterial killing in the surrounding medium with irradiation. As a result, starting from an initial $10^{10} \mathrm{CFU} \mathrm{mL}^{-1}$ bacterial population, PIEO coatings prevent biofilm formation and reduce cell population surrounding the films by more than 2 logs without light and 4 logs after irradiation (see arrows in Fig. 9C), signifying a highly efficient antimicrobial activity.

\section{Conclusions}

This study demonstrates for the first time that eosin can be used both as a photoinitiator for the polymerization of PEG-acrylate networks and as an antibacterial agent against $E$. coli and $S$. aureus. The photodynamic bacterial inactivation properties of these coatings limited bacterial colonization up to $6 \mathrm{~h}$ under visible light while their eosin-releasing ability extended their antibacterial surface properties for $16 \mathrm{~h}$ in the dark. After this period, they also showed a photo-induced bactericidal activity against the surrounding $S$. aureus cells. The presence of amines enabled the elaboration of eosin-containing PEG-acrylate films without an additional photoinitiator, but their antibacterial properties were lower due to both better cell adhesion and intrinsic ability to deactivate singlet oxygen. While the heredescribed new material may advantageously be used as a coating on one-time used medical devices, our demonstration that eosin can act as both an initiator of the polymerization and an antibacterial agent with dual properties should trigger further investigations of the photochemistry of antibiotics in a material design perspective.

\section{Competing financial interests}

The authors declare no competing financial interests.

\section{Authors' contribution}

This manuscript was written through contributions from all authors. All authors have given approval to the final version of the manuscript.

\section{Acknowledgements}

We would like to thank the CNRS Institute, the University of Paris-Est Creteil and the Politecnico School of doctorate for financial support.

\section{References}

1 J. G. Thomas, I. Litton and H. Harald Rinde, in Biofilms, Infection, and Antimicrobial Therapy, ed. J. L. Pace, M. E. Rupp and R. G. Finch, CRC Press Taylor and Francis Group, 2006, ch. 2, pp. 21-39.

2 G. Ducel, J. Fabry and L. Nicolle, Prevention of hospitalacquired infections: a practical guide, World Health Organization, 2002.

3 J. C. Tiller, C. J. Liao, K. Lewis and A. M. Klibanov, Proc. Natl. Acad. Sci. U. S. A., 2001, 98, 5981.

4 K. Bazaka, M. V. Jacob, R. J. Crawford and E. P. Ivanova, Appl. Microbiol. Biotechnol., 2012, 95, 299.

5 C. R. Arciola, D. Campoccia, P. Speziale, L. Montanaro and J. W. Costerton, Biomaterials, 2012, 33, 5967.

6 H. F. Chambers and F. R. DeLeo, Nat. Rev. Microbiol., 2009, 7, 629 .

7 H. Grundmann, M. Ires-de-Sousa, J. Boyce and E. Tiemersma, Lancet, 2006, 368, 874.

8 R. M. Klevens, M. A. Morrison, J. Nadle, S. Petit, K. Gershman, S. Ray, L. H. Harrison, R. Lynfield, G. Dumyati, J. M. Townes, A. S. Craig, E. R. Zell, G. E. Fosheim, L. K. McDougal, R. B. Carey and S. K. Fridkin, JAMA, 2007, 298, 1763.

9 T. L. Smith, M. L. Pearson, K. R. Wilcox, C. Cruz, M. V. Lancaster, B. Robinson-Dunn, F. C. Tenover, M. J. Zervos, J. D. Band, E. White and W. R. Jarvis, N. Engl. J. Med., 1999, 340, 493.

10 S. Krishnan, C. J. Weinman and C. K. Ober, J. Mater. Chem., 2008, 18, 3405.

11 I. Banerjee, R. C. Pangule and R. S. Kane, Adv. Mater., 2011, 23, 690.

12 G. Cheng, Z. Zhang, S. Chen, J. D. Bryers and S. Jiang, Biomaterials, 2007, 28, 4192.

13 R. Poupart, A. Haider, J. Babinot, I. K. Kang, J. P. Malval, J. Lalevée, S. A. Andalloussi, V. Langlois and D. L. Versace, ACS Biomater. Sci. Eng., 2015, 1, 525.

14 G. M. Manecka, J. Labrash, O. Rouxel, P. Dubot, J. Lalevée, S. A. Andaloussi, E. Renard, V. Langlois and D. L. Versace, ACS Sustainable Chem. Eng., 2014, 2, 996.

15 M. Ignatova, K. Starbova, N. Markova, N. Manolova and I. Rashkov, Carbohydr. Res., 2006, 341, 2098.

16 M. Ignatova, Z. Petkova, N. Manolova, N. Markova and I. Rashkov, Macromol. Biosci., 2012, 12, 104.

17 S. El Habnouni, V. Darcos, X. Garric, J.-P. Lavigne, B. Nottelet and J. Coudane, Adv. Funct. Mater., 2011, 21, 3321.

18 C. Lorenzini, A. Haider, I.-K. Kang, M. Sangermano, S. Abbad-Andalloussi, P.-E. Mazeran, J. Lalevée, E. Renard, V. Langlois and D.-L. Versace, Biomacromolecules, 2015, 16, 683 . 
19 T. T. Ruckh, R. A. Oldinski, D. A. Carroll, K. Mikhova, J. D. Bryers and K. C. Popat, J. Mater. Sci.: Mater. Med., 2012, 23, 1411.

20 M. L. W. Knetsch and L. H. Koole, Polymers, 2011, 3, 340-366.

21 D. Chung, S. E. Papadakis and K. L. Yam, Int. J. Food Sci. Technol., 2003, 38, 165.

22 Z. Markovic, B. Todorovic-Markovic, D. Kleut, N. Nikolic, S. Vranjes-Djuric, M. Misirkic, L. Vucicevic, K. Janjetovic, A. Isakovic, L. Harhaji, B. Babic-Stojic, M. Dramicanin and V. Trajkovic, Biomaterials, 2007, 28, 5437.

23 M. Condat, J. Babinot, S. Tomane, J.-P. Malval, I.-K. Kang, F. Spillebout, P.-E. Mazeran, J. Lalevee, S. A. Andalloussi and D.-L. Versace, RSC Adv., 2016, 6, 18235.

24 M. Condat, P. E. Mazeran, J. P. Malval, J. Lalevee, F. MorletSavary, E. Renard, V. Langlois, S. Abbad Andalloussi and D. L. Versace, $R S C A d v$., 2015, 5, 85214.

25 A. Valkov, F. Nakonechny and M. Nisnevitch, Int. J. Mol. Sci., 2014, 15, 14984.

26 M. Tim, J. Photochem. Photobiol., B, 2015, 150, 2.

27 R. Cahan, R. Schwartz, Y. Langzam and Y. Nitzan, Photochem. Photobiol., 2011, 87, 1379.

28 B. Aveline, Compr. Ser. Photosci., 2001, 2, 17.

29 G. Jori, C. Fabris, M. Soncin, S. Ferro, O. Coppellotti, D. Dei, L. Fantetti, G. Chiti and G. Roncucci, Lasers Surg. Med., 2006, 38, 468.

30 M. Cloutier, D. Mantovani and F. Rosei, Trends Biotechnol., 2015, 33, 637.

31 F. Nakonechny, A. Pinkus, S. Hai, O. Yehosha, Y. Nitzan and M. Nisnevitch, Photochem. Photobiol., 2013, 89, 671.

32 V. Decraene, J. Pratten and M. Wilson, Infect. Control. Hosp. Epidemiol., 2008, 29, 1181.

33 V. Decraene, J. Pratten and M. Wilson, Curr. Microbiol., 2008, 57, 269.

34 A. Felgenträger, T. Maisch, A. Späth, J. A. Schröder and W. Bäumler, Phys. Chem. Chem. Phys., 2014, 16, 20598.

35 S. V. Jenkins, A. Srivatsan, K. Y. Reynolds, F. Gao, Y. Zhang, C. D. Heyes, R. K. Pandey and J. Chen, J. Colloid Interface Sci., 2016, 461, 225.

36 J.-P. Fouassier, F. Morlet-Savary, J. Lalevée, X. Allonas and C. Ley, Materials, 2010, 3, 5130.

37 K. Marinic, D. Manoil, A. Filieri, J. C. Wataha, J. Schrenzel, N. Lange and S. Bouillaguet, Photodiagn. Photodyn. Ther., 2015, 12, 393.

38 B. D. Mather, K. Viswanathan, K. M. Miller and T. E. Long, Prog. Polym. Sci., 2006, 31, 487.

39 D. P. Nair, M. Podgórski, S. Chatani, T. Gong, W. Xi, C. R. Fenoli and C. N. Bowman, Chem. Mater., 2014, 26, 724.

40 N. B. Colthup, L. H. Daly and S. E. Wiberley, Introduction to Infrared and Raman Spectroscopy, Academic Press, San Diego, 3rd edn, 1990, ch. 5, pp. 215-235.
41 J.-P. Malval, C. Chaimbault, B. Fischer, J.-P. Morand and R. Lapouyade, Res. Chem. Intermed., 2001, 27, 21.

42 D. Rehm and A. Weller, Isr. J. Chem., 1970, 8, 259.

43 J.-P. Fouassier and J. Lalevée, Reactivity of Radicals toward Oxygen, Hydrogen Donors, Monomers, and Additives: Understanding and Discussion, Wiley-VCH Verlag GmbH, Weinheim, 2012, ch. 18, pp. 399-455.

44 E. Andrzejewska, D. Zych-Tomkowiak, M. Andrzejewski, G. L. Hug and B. Marciniak, Macromolecules, 2006, 39, 3777.

45 C. E. Hoyle and K.-J. Kim, J. Radiat. Curing, 1985, 12, 9.

46 D.-L. Versace, J.-P. Fouassier and J. Lalevée, Macromol. Rapid Commun., 2014, 35, 821.

47 M. Neumann, S. Füldner, B. König and K. Zeitler, Angew. Chem., Int. Ed., 2011, 50, 951.

48 W. Decheng, L. Ye, H. Chaobin, C. Taishung and G. Suathong, Macromolecules, 2004, 37, 6763.

49 C. Gao and D. Yan, Prog. Polym. Sci., 2004, 29, 183.

50 G. González, X. Fernández-Francos, À. Serra, M. Sangermano and X. Ramis, Polym. Chem., 2015, 6, 6987.

51 D. J. Balazs, K. Triandafillu, P. Wood, Y. Chevolot, C. van Delden, H. Harms, C. Hollenstein and H. J. Mathieu, Biomaterials, 2004, 25, 2139.

52 P. J. Eginton, H. Gibson, J. Holah, P. S. Handley and P. Gilbert, J. Ind. Microbiol., 1995, 15, 305.

53 G. E. Cohn and H. Y. Tseng, Photochem. Photobiol., 1977, 26, 465.

54 T. A. Dahl, W. R. Midden and P. E. Hartman, Photochem. Photobiol., 1987, 46, 345.

55 R. G. Chapman, E. Ostuni, S. Takayama, R. E. Holmlin, L. Yan and G. M. Whitesides, J. Am. Chem. Soc., 2000, 122, 8303.

56 R. G. Chapman, E. Ostuni, M. N. Liang, G. Meluleni, E. Kim, L. Yan, G. Pier, H. S. Warren and G. M. Whitesides, Langmuir, 2001, 17, 1225.

57 C. Tanielian, L. Golder and C. Wolff, J. Photochem., 1984, 25, 117.

58 D. Y. C. Fung and R. D. Miller, Appl. Microbiol., 1973, 25, 793.

59 J. G. Holt, N. R. Krieg, P. H. Sneath, J. T. Safety and S. T. Williams, in Bergey's Manual of Determinative Bacteriology, K. Williams and O. Wilkins, Baltimore, USA, 9th edn, 1993.

60 K. E. Sanderson, T. MacAlister, J. W. Costerton and K. J. Cheng, Can. J. Microbiol., 1974, 20, 1135.

61 T. A. Dahl, W. R. Midden and P. E. Hartman, Photochem. Photobiol., 1988, 47, 357.

62 R. C. Straight and J. D. Spikes, in Singlet oxygen, ed. A. A. Frimer, CRC Press, Inc., Boca Raton, Florida, 1985, vol. IV, pp. 91-143. 